\title{
QUANTIFICAÇÃO DE STAPHYLOCOCCUS AUREUS, ESCHERICHIA COLI E MECANISMOS DE RESISTÊNCIA NAS MÃOS DE MANIPULADORES DE ALIMENTOS EM UANS HOSPITALARES EM SC ${ }^{1}$
}

\author{
QUANTIFICATION OF STAPHYLOCOCCUS AUREUS, \\ ESCHERICHIA COLI AND RESISTANCE MECHANISMS IN \\ THE HANDS OF FOOD HANDLERS IN HOSPITAL UANS IN SC
}

\author{
Gabriela Maestri², Tatiana Bender Schmeling ${ }^{3}$, \\ Daniela Valcarenghi ${ }^{4}$ e Marla de Paula Lemos ${ }^{5}$
}

\section{RESUMO}

Os manipuladores de alimentos podem ser transmissores de agentes patogênicos, pois suas mãos entram em contato direto com os alimentos. Em hospitais, a contaminação por Staphylococcus aureus e Escherichia coli apresentam risco biológico maior devido à resistência aos antibióticos. Este trabalho objetivou quantificar S.aureus e E.coli nas mãos de manipuladores de alimentos de UAN hospitalares em dois municípios do litoral catarinense, bem como verificar se apresentavam os mecanismos de resistência do tipo Staphylococcus aureus Resistente a Meticilina (MRSA) e Enterobactérias Resistentes aos Carbapenêmicos (ERC). Tratou-se de uma pesquisa observacional transversal. Amostras das mãos de trinta manipuladores foram coletadas em três unidades hospitalares denominadas em A, B e C. Foi utilizado o método de contagem em superfície e identificação através de meios cromogênicos para os mecanismos de resistência. Os resultados demonstraram contaminação por S.aureus em duas amostras (6,66\%) enquanto que nenhuma amostra foi identificada E.coli. Quanto à resistência, uma amostra (3,33\%) apresentou MRSA e duas amostras $(6,66 \%)$ demonstraram a presença de ERC. Das unidades avaliadas, a $C$ não apresentou crescimento dos micro-organismos analisados. A unidade A apresentou crescimento exclusivamente de ERC (10\%) e a unidade B revelou contaminação por S.aureus (20\%), MRSA (10\%) e ERC (10\%). Conclui-se que a contaminação encontrada nas mãos dos manipuladores de alimentos e os mecanismos de resistências demonstraram a necessidade de maior frequência e competência na higienização das mãos, sendo de extrema relevância a necessidade de supervisão e conscientização destes profissionais quanto a higiene pessoal.

Palavras-chave: Higiene das mãos, Staphylococcus aureus Resistente à Meticilina, Enterobacteriaceas Resistentes a Carbapenêmicos.

\section{ABSTRACT}

Food handlers can be pathogen carriers because their hands come into direct contact with food. In hospitals, contamination with Staphylococcus aureus and Escherichia coli present a higher biological risk due to antibiotic resistance. This study aimed to quantify the presence of Staphylococcus aureus and Escherichia coli in the hands of food handlers working at Food and Nutrition Services in two municipalities of the coast of the

\footnotetext{
${ }^{1}$ Trabalho de Conclusão de Curso.

${ }^{2}$ Informações do Autor: Gabriela Maestri. Acadêmica do Curso de Nutrição. Universidade do Vale do Itajaí - UNIVALI. E-mail: gaabi_maestri@hotmail.com

${ }^{3}$ Informações do Coorientador: Tatiana Bender Schmeling. Bióloga. Universidade do Vale do Itajaí - UNIVALI. E-mail: tatbem@univali.br

${ }^{4}$ Informações do Colaborador: Daniela Valcarenghi. Farmacêutica. Universidade do Vale do Itajaí - UNIVALI. E-mail: danivalca@univali.br

${ }^{5}$ Informações do Orientador: Marla de Paula Lemos. Nutricionista. Universidade do Vale do Itajaí - UNIVALI. E-mail: mlemos@univali.br
} 
state of Santa Catarina, as well as to verify whether these pathogens had Methicillin-resistant Staphylococcus aureus (MRSA) and Carbapenem-resistant Enterobacteria (CRE) resistance mechanisms. It was a cross-sectional observational research. Samples from the hands of thirty food handlers were collected in three hospital units named $A, B$ and $C$. The method of surface counting and chromogenic identification means for the resistance mechanisms was used. Results revealed contamination by Staphylococcus aureus in two samples (6.66\%), while no sample was identified with contamination by Escherichia coli. For resistance, one sample (3.33\%) showed MRSA and two samples (6.66\%) showed the presence of CRE. Of the units evaluated, there was no growth of the analyzed microorganisms in Hospital C. Services in Hospital A presented growth of CRE (10\%) only and Hospital B showed contamination by Staphylococcus aureus (20\%), MRSA (10\%) and ERC (10\%). It is concluded that the contamination found in the hands of food handlers and the resistance mechanisms demonstrated the need for greater frequency and mastery in hand hygiene, being of extreme relevance the need for supervision and awareness of these professionals regarding personal hygiene.

Keywords: Hand Hygiene, Methicilin-Resistant Staphylococcus aureus, Carbapenem-Resistant Enterobacteriaceae.

\section{INTRODUÇÃO}

Segundo a Resolução da Diretoria Colegiada (RDC) 216/2004, manipuladores de alimentos são pessoas que atuam no serviço de alimentação entrando em contato direto ou indireto com o alimento, devendo seguir numerosas regras de boas práticas com o objetivo de garantir a qualidade do alimento produzido, em âmbito nutricional e/ou higienicossanitário. O manipulador é fundamental na segurança dos alimentos, pois, em contato com os alimentos, pode se tornar um importante transmissor de agentes patogênicos principalmente por meio de suas mãos que são potentes veículos quando contaminadas (BRASIL, 2004) (MEDEIROS; CARVALHO; FRANCO, 2017).

No ambiente hospitalar, as internações prolongadas e usos de procedimentos invasivos tornam os pacientes mais susceptíveis a Infecções Relacionadas à Assistência à Saúde (IRAS). Estas, por sua vez, acometem cerca de $16 \%$ dos pacientes hospitalizados, sendo seu principal meio de transmissão as mãos contaminadas, pois são fonte e veículo de transmissão de micro-organismos. Desta forma, podem aumentar o tempo de permanência dos pacientes na instituição sendo também responsáveis por parte da taxa de mortalidade, pois no ambiente hospitalar o uso de antibióticos sem análise de eficácia e sem confirmação de antibiogramas promove ou potencializa a resistência bacteriana (ROCHA, 2007) (BRASIL, 2004) (BRASIL, 2017) (MENEZES; PORTO; PIMENTA, 2016).

É essencial capacitar os manipuladores de alimentos sobre os cuidados na aquisição, acondicionamento e manipulação para assegurar a qualidade sanitária dos alimentos para que não ofereça risco por perigo químico, físico e/ou biológico. Consequentemente, as boas práticas de manipulação são regras que quando empregadas auxiliam na redução dos perigos já citados e até a contaminação (MARMENTINI; RONQUI; ALVARENGA, 2010). É de atribuição do responsável do setor de alimentação realizar capacitações, assegurar a higiene dos manipuladores, das matérias-primas, das instalações e das técnicas de preparo, para assim garantir a segurança dos alimentos (SILVA JÚNIOR, 2014). 
Segundo Silva Júnior (2014) as Doenças Transmitidas por Alimentos (DTAs) são consequentes da ingestão de agentes biológicos, químicos ou físicos presentes nos alimentos. Entre os principais micro-organismos causadores das DTAs encontram-se Staphylococcus aureus e Coliformes a $45^{\circ} \mathrm{C}$ (Escherichia coli), ambos pertencentes à microbiota das mãos, sendo S.aureus microbiota residente e E.coli microbiota transitória.

A microbiota transitória ocupa a parte externa da pele, sobrevive por um curto período de tempo sendo removida pela higienização correta das mãos. É adquirida pelos profissionais de saúde durante o contato direto com o paciente, ambiente, produtos e equipamentos contaminados. Constitui-se por micro-organismos não patogênicos ou potencialmente patogênicos como bactérias, fungos e vírus que não se multiplicam na pele, porém podem causar infecções relacionados à IRAS. Enquanto, a microbiota residente está nas camadas mais profundas da pele, sendo mais resistente no processo de higienização. As mãos dos profissionais de saúde podem ser colonizadas por micro-organismos patogênicos, que em pacientes imunossuprimidos, cirúrgicos ou de UTI, podem apresentar importante risco de infecção (BRASIL, 2009).

A intoxicação ocasionada por Staphylococcus aureus é causada pela ingestão de toxinas presente nos alimentos, produzidas por este micro-organismo. Essas toxinas são resistentes à cocção e a hidrólise pelas enzimas gástricas e jejunais. Os reservatórios deste micro-organismo são os seres humanos e animais de sangue quente, pois fazem parte da microbiota da pele, mucosa, trato respiratório e gastrointestinal (PROCOP, 2019) (CUNHA; CUNHA, 2007). Os meios de contaminação podem ocorrer por manipular os alimentos após a cocção e alimentos já higienizados sem o devido cuidado, como tossir em cima do alimento, bem como utilizar panos de copa contaminados (SILVA JÚNIOR, 2014).

O grupo dos Coliformes a $45^{\circ} \mathrm{C}$, no qual a E.coli pertence é composto por bacilos gram-negativos fermentadores de glicose, pertencente à família Enterobacteriaceae, que não apresentam capacidade de produzir esporos, porém conseguem se proliferar em ambientes contendo presença de sais biliares ou outros compostos ativos. São frequentemente encontrados no trato intestinal de humanos e alguns animais de sangue quente (PROCOP, 2019) (CONTE et a, 2004) (SANTOS; RANGEL; AZEVERO, 2010). Os mecanismos de contaminação podem ser através da contaminação cruzada entre os alimentos crus e cozidos, utensílios não desinfetados e mãos de manipuladores não higienizadas, bem como são considerados indicadores de contaminação fecal (SILVA JÚNIOR, 2014).

A higienização das mãos é o processo de fricção manual de toda a superfície, punhos e dedos, utilizando sabonete e água corrente sendo finalizado com álcool $70 \%$, por aproximadamente trinta segundos. Tem como objetivo remover a maior quantidade de micro-organismos da microbiota transitória e de alguns micro-organismos residentes, bem como pelos, células descamativas, suor, sujidade e oleosidade (BRASIL, 2009).

A resistência aos antibióticos se desenvolve como uma natural consequência da habilidade da população bacteriana de se adaptar. $\mathrm{O}$ uso indiscriminado de antibióticos aumenta a pressão seletiva 
e, também, a oportunidade de a bactéria ser exposta aos mesmos, facilitando a aquisição de mecanismos de resistência. A resistência aos antibióticos é inevitável e irreversível, visto que o uso intenso de antibióticos na medicina, na produção de alimentos para animais e na agricultura tem causado um aumento na resistência aos antibióticos em todo mundo. No Brasil, o panorama da resistência bacteriana é preocupante e o crescente surgimento de novas cepas de bactérias multirresistentes nos hospitais brasileiros vem causando preocupação ao sistema de saúde (MENEZES; PORTO; PIMENTA, 2016). Dentre estes, encontram-se o Staphylococcus aureus Resistente a Meticilina (MRSA) e as Enterobactérias Resistentes aos Carbapenêmicos (ERC).

As infecções causadas pelo MRSA adquiridas em hospitais estão sendo documentadas de forma crescente em todo o mundo. São provenientes do mecanismo de resistência a beta-lactâmicos e está relacionado ao desenvolvimento de uma Proteína Ligadora de Penicilina (PLP) que não possui afinidade por antibióticos desta classe. A codificação dessas novas PLPs tornam esses patógenos resistentes ao antibiótico oxacilina e está associado à aquisição do gene mecA, o qual faz parte de um elemento genético móvel detectado em isolados resistentes ao antibiótico meticilina (FELDHAUS et al., 2016) (SILVA, 2011).

O mecanismo de resistência aos carbapenêmicos se deu através de mutações genéticas como fator de sobrevivência bacteriana. A enzima carbapenemase atribui resistência a todos os agentes beta-lactâmicos como cefalosporinas, penicilinas, monobactâmicos e a carbapenêmicos. Este mecanismo ocorre mais frequentemente em enterobactérias, sendo principalmente nos gêneros Klebsiella, Enterobacter, Escherichia, Serratia, Citrobacter, Salmonella, Proteus e na espécie Morganella morganii. A detecção precoce de pacientes infectados por ERC, em especial a E.coli é de grande relevância, visto que esse micro-organismo pode causar graves infecções, principalmente no ambiente hospitalar (SEIBERT et al., 2014) (GAUTHIER et al., 2018).

A Comissão de Controle de Infecção Hospitalar (CCIH) reúne profissionais que tenham conhecimento no assunto de bacteriologia e epidemiologia para que possam atuar de forma efetiva. Em hospitais de pequeno porte, a responsabilidade pode ser adquirida por apenas um profissional que detenha tais conhecimentos. Entretanto, nos hospitais de médio e grande porte, a CCIH reúne uma equipe multidisciplinar. As funções destinadas a essa Comissão estão intimamente relacionadas às fontes e causas das infecções hospitalares objetivando a redução da incidência de infecções dentro deste ambiente. As atribuições de relevância das CCIHs são o controle do ambiente, do pessoal e de produtos químicos, bem como a elaboração de normas de rotina, a investigação epidemiológica e a realização de reuniões periódicas, tudo isso visando o maior controle da disseminação dos micro-organismos (CORREA et al., 2017).

Considerando a possibilidade de haver micro-organismos multirresistentes na microbiota contaminante, este trabalho objetivou quantificar os Staphylococcus aureus e Escherichia coli nas mãos de manipuladores de alimentos de UANs hospitalares em dois municípios do litoral catarinense, bem 
como verificar se estes apresentavam os mecanismos de resistência do tipo Staphylococcus aureus Resistente a Meticilina (MRSA) e Enterobactérias Resistentes aos Carbapenêmicos (ERC).

\section{MATERIAL E MÉTODOS}

Tratou-se de uma pesquisa observacional transversal que visou quantificar Staphylococcus aureus, Escherichia coli e possíveis mecanismos de resistências associados à elas do tipo MRSA e ERC nas mãos de manipuladores de alimentos em UANs hospitalares.

Hospitais de dois municípios do litoral catarinense foram convidados a participar da pesquisa a partir do envio da carta convite a sua direção e/ou contato presencial quando solicitado pela equipe de Comissão de Controle de Infecção Hospitalar (CCIH) e nutricionista responsável pelo Serviço de Nutrição e Dietética (SND). Destes hospitais, três unidades aceitaram participar da pesquisa, designados em A, B e C por meio do Termo de Anuência da Instituição.

Quanto à coleta das amostras, foi solicitado antecipadamente que os manipuladores de alimentos assinassem o Termo de Consentimento Livre e Esclarecido - TCLE e posteriormente higienizassem suas mãos conforme orientação recebida pelo responsável do setor. Para padronização das amostras, definiu-se o número de colaboradores da menor equipe, sendo que as demais unidades os colaboradores foram selecionados previamente pela nutricionista responsável. Este estudo foi aprovado pelo Comitê de Ética em Pesquisa da Universidade do Vale do Itajaí sob o parecer de número 2.789.789.

Foram coletadas amostras das duas mãos de cada manipulador, com o auxílio de suabes estéreis. Estes, foram friccionados nas mãos de forma circular entrando em contato por toda a palma e superfície dos dedos e acondicionados em um tubo de ensaio contendo $1 \mathrm{~mL}$ de solução salina fosfatada tamponada. As amostras foram transportadas em caixa isotérmica ao Laboratório de Microbiologia da Escola de Ciências da Saúde em uma Universidade do Vale do Itajaí, localizada em Itajaí, SC, para a execução das análises.

Para a verificação do mecanismo de resistência do Staphylococcus aureus a meticilina (MRSA) foi seguido o protocolo do laboratório fornecedor do meio de cultura do Agar Cromogênico MRSA (LABORCLIN, 2017). A amostra foi coletada com auxílio de outro suabe e inoculada pela técnica de esgotamento no referido meio de cultura e incubada invertida em estufa bacteriológica a $35^{\circ} \mathrm{C}$ por 24 horas. Colônias resistentes ao antibiótico meticilina apresentaram cor azul a verde no meio de cultura. Prova de coagulase foi realizada nas colônias suspeitas.

Para a verificação do mecanismo de resistência de E.coli e/ou possíveis enterobactérias frente aos carbapenêmicos, outro suabe foi coletado das mãos dos manipuladores de alimentos e imediatamente inoculado pela técnica de esgotamento no meio de cultura Agar Cromogênico. Este por sua vez foi incubado invertido em estufa bacteriológica a $35^{\circ} \mathrm{C}$ por 24 horas. Colônias resistentes aos carbapenêmicos apresentaram crescimento no meio de cultura de cor verde escura a azul metálico 
caracterizando através do meio cromogênico os gêneros Klebsiella, Enterobacter e Citrobacter (LABORCLIN, 2017).

Para a contagem de Staphylococcus aureus, $0,1 \mathrm{~mL}$ da amostra foi inoculada pela técnica de superfície com o auxílio de alça de Drigalski contendo o meio de cultura Baird Parker previamente preparado e esterilizado. Estas foram incubadas invertidas em estufa bacteriológica por $24-48$ horas a $35^{\circ} \mathrm{C}$. Colônias características de cor negra, contendo halo opaco e/ou halo transparente ao seu redor foram contadas e desta forma determinado o valor em Unidade Formadora de Colônia (UFC) / mãos. A confirmação destas se deu pelo teste da coagulase positiva (SALLES; GOULART, 1997) (PROCOP, 2019).

Para a contagem de E.coli, $0,1 \mathrm{~mL}$ da amostra foi inoculada pela técnica de superfície com o auxílio de alça de Drigalski contendo o meio de cultura MacConkey previamente preparado e esterilizado (DUTRA; CAMPOS, 2017).

A quantificação de ambos os micro-organismos foi realizada através da contagem direta em placa e o resultado expresso em Unidade Formadora de Colônia - UFC/mãos.

Os dados foram tabulados e analisados em planilhas do programa Microsoft Office Excel 2013 e os resultados expressos em frequências absolutas e relativas.

Até o presente momento, não consta na Legislação brasileira parâmetros para determinar a contagem dos micro-organismos em análises de mãos, embora a Organização Panamericana de Saúde (OPAS) (2006) sugira que o limite máximo seja de $10^{2} \mathrm{UFC} /$ mãos para S.aureus enquanto Tondo e Bartz (2019) propõe ausência de E.coli nas mãos analisadas.

\section{RESULTADOS E DISCUSSÃO}

Foram coletadas amostras das mãos de 30 (trinta) manipuladores de alimentos distribuídos entre as unidades A, B e C, sendo $70 \%(n=21)$ copeiras e $30 \%(n=9)$ auxiliares de cozinha, conforme demonstra a tabela 1 .

Tabela 1 - Quantificação e mecanismos de resistências de S.aureus e E.coli nas mãos de manipuladores de alimentos em UANs hospitalares de dois municípios do litoral catarinense.

\begin{tabular}{ccccccc}
\hline UAN & Amostra & Função & $\begin{array}{c}\text { S.aureus (OPAS, 2006: } \\
<\mathbf{1 0}^{\mathbf{2}} \mathbf{U} \text { FC/mãos) }\end{array}$ & $\begin{array}{c}\text { MRSA } \\
\text { E.coli (TONDO et al., } \\
\text { 2019: ausência) }\end{array}$ & ERC \\
\hline A & $\mathbf{0 0 1}$ & Copeira & 2 & - & 0 & - \\
A & $\mathbf{0 0 2}$ & Auxiliar de Cozinha & 1 & - & 0 & - \\
A & $\mathbf{0 0 3}$ & Copeira & 7 & - & 0 & + \\
A & $\mathbf{0 0 4}$ & Copeira & 4 & - & 0 & - \\
A & $\mathbf{0 0 5}$ & Auxiliar de Cozinha & 0 & - & 0 & - \\
A & $\mathbf{0 0 6}$ & Copeira & 5 & - & 0 & - \\
A & $\mathbf{0 0 7}$ & Auxiliar de Cozinha & 14 & - & 0 & - \\
A & $\mathbf{0 0 8}$ & Copeira & 0 & - & 0 & - \\
A & $\mathbf{0 0 9}$ & Copeira & 1 & - & 0 & - \\
\hline
\end{tabular}




\begin{tabular}{|c|c|c|c|c|c|c|}
\hline A & 010 & Auxiliar de Cozinha & 18 & - & 0 & - \\
\hline B & 011 & Copeira & 135 & - & 0 & - \\
\hline B & 012 & Copeira & 300 & + & 0 & - \\
\hline B & 013 & Copeira & 71 & - & 0 & - \\
\hline B & 014 & Copeira & 13 & - & 0 & - \\
\hline B & 015 & Auxiliar de Cozinha & 14 & - & 0 & - \\
\hline B & 016 & Copeira & 6 & - & 0 & - \\
\hline B & 017 & Auxiliar de Cozinha & 4 & - & 0 & + \\
\hline B & 018 & Copeira & 7 & - & 0 & - \\
\hline B & 019 & Auxiliar de Cozinha & 1 & - & 0 & - \\
\hline B & 020 & Copeira & 5 & - & 0 & - \\
\hline $\mathrm{C}$ & 021 & Copeira & 4 & - & 0 & - \\
\hline $\mathrm{C}$ & 022 & Auxiliar de Cozinha & 0 & - & 0 & - \\
\hline $\mathrm{C}$ & 023 & Copeira & 11 & - & 0 & - \\
\hline $\mathrm{C}$ & 024 & Copeira & 1 & - & 0 & - \\
\hline $\mathrm{C}$ & 025 & Copeira & 0 & - & 0 & - \\
\hline $\mathrm{C}$ & 026 & Copeira & 20 & - & 0 & - \\
\hline $\mathrm{C}$ & 027 & Copeira & 0 & - & 0 & - \\
\hline $\mathrm{C}$ & 028 & Copeira & 55 & - & 0 & - \\
\hline $\mathrm{C}$ & 029 & Auxiliar de Cozinha & 13 & - & 0 & - \\
\hline $\mathrm{C}$ & 030 & Copeira & 23 & - & 0 & - \\
\hline
\end{tabular}

UAN: Unidade de Alimentação e Nutrição

UFC: Unidade Formadora de Colônias

MRSA: Staphylococcus aureus Resistente a Meticilina

ERC: Enterobactérias Resistentes aos Carbapenêmicos

Considerando o total de amostras independente das unidades, na tabela 1 pode ser observado que $83,33 \%(\mathrm{n}=25)$ das amostras das mãos estavam colonizadas por S.aureus. Destas, 6,66\% $(\mathrm{n}=2)$ apresentaram contaminação superior a $10^{2} \mathrm{UFC} / \mathrm{mãos}$, sendo estes copeiras de uma das unidades. Estes profissionais representam maior risco de infecções aos hospitalizados, pois entram em contato direto com o paciente (HAMADA et al., 2016).

Corroborando aos achados, Ponath e colaboradores (2016) avaliaram a presença de S.aureus, Coliformes totais e mesófilos em 15 amostras de mãos de manipuladores de alimentos na cidade de Ji-Paraná no estado de Rondônia e constataram que todas as amostras das mãos de manipuladores apresentaram um nível acima de $10^{2}$ UFC/mão para os micro-organismos avaliados, à medida que neste estudo somente o micro-organismo S.aureus indicou contagem superior a preconizada pela OPAS (2006).

Kochanski e colaboradores (2009) avaliaram as condições microbiológicas de 8 ambientes, mãos de 6 manipuladores de alimentos e 4 utensílios e equipamentos, analisando o risco de possível contaminação por micro-organismo em uma UAN, que retratou como resultado principal a contaminação por S.aureus em todos os manipuladores de alimentos. Em contra partida, no presente estudo, apenas dois manipuladores encontravam-se contaminados pelo micro-organismo.

A presença de contaminação por este micro-organismo demonstra antissepsia inadequada dos manipuladores. É possível corrigir a falha deste processo seguindo-se o protocolo intitulado 
"Segurança do paciente em serviços de saúde: Higienização das mãos", bem como através da RDC $n^{\circ}$ 42/2010, ambos instituídos pela Agência Nacional de Vigilância Sanitária (ANVISA) (BRASIL, 2009) (BRASIL, 2010).

Segundo o Codex Alimentarius da OPAS (2006) os manipuladores devem sempre lavar as mãos quando seu nível de limpeza puder comprometer a qualidade dos alimentos, sendo imediatamente antes de manipular alimentos, após qualquer interrupção, após tocar materiais contaminados, após usar o banheiro ou em qualquer outra situação em que houver necessidade. No presente trabalho todas as unidades possuíam lavatórios exclusivos de higienização das mãos em locais estratégicos no local de produção, munidos de produtos de higiene como sabonete líquido inodoro, produto antisséptico e toalhas de papel não reciclado além de coletores de resíduos dotados de tampa com acionamento não manual.

Quanto a quantificação de E.coli, não houve crescimento nas amostras analisadas. Tal resultado evidencia que não houve contaminação fecal, porém, deficiência no processo de higienização das mãos. Em contraposição aos achados, Leão e colaboradores (2018) avaliaram a presença de enteroparasitos e Coliformes termotolerantes nas mãos de 44 manipuladores de alimentos de UANs hospitalares e encontraram em 15,9\% das amostras presença de Coliformes termotolerantes, indicando contaminação das mãos dos manipuladores de alimentos e propensão à veiculação de agentes patógenos por esta via. Da mesma maneira que Carvalho Filho e colaboradores (2008) analisaram a qualidade microbiológica e físico-química da alimentação enteral não industrializada administrada em um hospital público da região Nordeste. Como resultado foi encontrado bactérias aeróbias mesófilas e Coliformes totais e fecais com significância nas mãos dos manipuladores, colocando em duvidas a seguridade do processo de manipulação.

Zancanaro e colaboradores (2017) realizaram a contagem de Staphylococcos aureus nas mãos de 4 lactaristas de um hospital e encontraram 100\% de colonização pelo micro-organismo, sendo estas 50\% contaminadas, além de ser observado a falta de padronização nos procedimentos de higienização, bem como a falta de produtos de higiene.

Ayçiçek e colaboradores (2004) avaliaram o nível de contaminação bacteriana nas mãos de 30 manipuladores de alimentos de um hospital de treinamento militar. Foram colhidas 180 amostras das mãos nuas e enluvadas. Constataram a presença de S.aureus em 70\% (n=126) e contaminação por E.coli $\mathrm{em} 10,5 \%(\mathrm{n}=19)$ das amostras.

Entretanto, Rubin e colaboradores (2012) avaliaram microbiologicamente mãos, utensílios e superfícies dos manipuladores de alimentos de 15 unidades e encontraram a presença de E.coli e S.aureus nas mãos de somente um manipulador de alimento.

Estudo realizado por Gauer e Silva (2017) que investigaram a contaminação microbiana nas mãos de 29 funcionários de um posto de saúde em uma cidade do interior do Rio Grande do Sul, concluindo que os ambientes de assistência à saúde são meio de concentração, transmissão e disseminação de micro-organismos patogênicos, principalmente S.aureus e E.coli. 
Para os mecanismos de resistência analisados conforme demonstra a tabela $1,3,33 \%(n=1)$ apresentou crescimento para MRSA e 6,66\% $(n=2)$ para ERC. Vários fatores colaboram para o desenvolvimento da resistência aos antibióticos, no entanto a sua prevenção depende da incorporação de práticas corretas às rotinas de assistência ao paciente, exigindo esforço idealizado pelas partes envolvidas. Diminuir o impacto dos micro-organismos portadores de resistência demanda ações envolvendo gestores de várias esferas, desde serviços públicos e particularidades até autoridades de saúde pública (CDC, 2012).

Analisando os resultados por UAN hospitalar, a tabela 2 demonstra que a unidade A apresentou crescimento unicamente de Enterobactérias Resistentes aos Carbapenêmicos ( $\mathrm{n}=1 ; 10 \%)$. Já na unidade B, houve crescimento tanto de S.aureus ( $\mathrm{n}=2 ; 20 \%)$, Staphylococcus aureus resistente a meticilina ( $\mathrm{n}=1 ; 10 \%)$ bem como de Enterobactérias Resistentes aos Carbapenêmicos (n=1;10\%). Em contrapartida, não houve crescimento de micro-organismos na unidade $\mathrm{C}$.

Tabela 2 - Prevalência de S.aureus, E.coli e respectivas resistências em UANs hospitalares de dois municípios do litoral catarinense.

\begin{tabular}{|c|c|c|c|c|c|}
\hline UAN & $\mathbf{N}$ & $\begin{array}{c}\text { S.aureus }>10^{2} \text { UFC/mãos } \\
\text { (OPAS, 2006: }<10^{2} \text { UFC/mãos) }\end{array}$ & MRSA & $\begin{array}{c}\text { E.coli (TONDO et al., } \\
\text { 2019: ausência) }\end{array}$ & ERC \\
\hline A & 10 & 0 & 0 & 0 & $10 \%(n=1)$ \\
\hline $\mathrm{B}$ & 10 & $20 \%(\mathrm{n}=2)$ & $10 \%(\mathrm{n}=1)$ & 0 & $10 \%(\mathrm{n}=1)$ \\
\hline $\mathrm{C}$ & 10 & 0 & 0 & 0 & 0 \\
\hline \multicolumn{6}{|c|}{ UAN: Unidade de Alimentação e Nutrição } \\
\hline \multicolumn{6}{|c|}{ N: Número de amostras } \\
\hline \multicolumn{6}{|c|}{ UFC: Unidade Formadora de Colônia } \\
\hline \multicolumn{6}{|c|}{ MRSA: Staphylococcus aureus Resistente a Meticilina } \\
\hline & & \multicolumn{4}{|c|}{ ERC: Enterobactérias Resistentes aos Carbapenêmicos } \\
\hline
\end{tabular}

A idade avançada, hospitalização em Unidade de Tratamento Intensivo (UTI) e o uso indiscriminado de antibióticos são fatores de risco para desencadear infecções por cepas de ERC, estando associada com o aumento da taxa de mortalidade em pacientes infectados (GUPTA et al., 2011). Dentre os principais antibióticos utilizados para o tratamento de infecções por ERC estão os beta-lactâmicos que respondem por mais de 65\% das prescrições (ELANDER, 2003) (MELETIS; BAGKERI, 2014). Sendo os carbapenêmicos os mais eficazes usados para tratamento de IRAS mais graves (NORDMANN; NASS; POIREL, 2011) (NORDMAN; DORTET; POIREL, 2012).

Custódio e colaboradores (2009) analisaram qualitativamente e quantitativamente micro-organismos presentes na microbiota das mãos de 48 profissionais de saúde de um hospital em Itubiara no estado de Goiás, no qual constaram em 44,5\% das amostras contaminação por Staphylococcus coagulase negativa (SCN) seguida de $40 \%$ de contaminação pelo micro-organimos S.aureus, do qual cerca de $70 \%$ dos Staphylococcus sp. foram resistentes a oxacilina. Assim como $6,66 \%$ das amostras analisadas no presente estudo possuíam resistência tipo MRSA. 
Estudo realizado por Martins e colaboradores (2009) que quantificaram e avaliaram o perfil de resistência de S.aureus em mãos de 100 manipuladores de alimentos, evidenciando que $24 \%$ dos manipuladores manifestaram presença deste micro-organismo, observando que $76 \%$ dos isolados demonstraram resistência múltipla e uma dessas foi resistente a 8 antibióticos. A elevada taxa de resistência múltipla representa risco potencial para a saúde pública pois dificulta o tratamento de inúmeras infecções e agravando quadros clínicos potencialmente curáveis.

Wiethan e Becker (2018) avaliaram a presença dos principais mecanismos de resistência em cocos gram positivos (MRSA) e bacilos gram negativos (resistência aos carbapenêmicos em enterobactérias) em 43 estudantes da graduação de medicina e encontraram incidência de $18 \%$ de MRSA nas fossas nasais dos estudantes.

Contribuindo aos resultados alcançados, Ferreira e colaboradores (2014) avaliaram a presença de S.aureus Resistentes a Meticilina em mãos e narina de 140 manipuladores de alimentos em 10 hospitais públicos em Salvador, Bahia. Destes, setenta (50\%) manipuladores estavam colonizados por S.aureus sendo $40(28,6 \%)$ dos colonizados apresentaram MRSA.

\section{CONCLUSÃO}

Conclui-se que do total de amostras, 6,66\% apresentaram contaminação por S.aureus superior a $10^{2} \mathrm{UFC} / \mathrm{mãos}$ e não ocorreu a presença de E.coli em nenhuma das amostras. Em contrapartida, Enterobactérias Resistentes aos Cabapenêmicos (ERC) foram detectadas em 10\% dos manipuladores da unidade A. Já na unidade B, S.aureus foi identificado como contaminante com valores superiores a $10^{2}$ UFC/mãos nas mãos dos manipuladores em $20 \%$ das mãos, sendo que destas, $10 \%$ foram resistentes ao antibiótico meticilina (MRSA). Outros 10\% dos manipuladores demonstraram a presença de Enterobactérias Resistentes aos Carbapenêmicos (ERC). Na unidade C não houve crescimento dos micro-organismos avaliados nas mãos dos manipuladores de alimentos. A contaminação pelo micro-organismo S.aureus nas mãos de manipuladores de alimentos em UANs hospitalares aliados a Resistência a Meticilina (MRSA), bem como a presença de ERC representam significativo risco hospitalar. A resistência dos micro-organismos é um problema crescente, coletivo e mundial que carece de atenção da saúde pública. É de extrema relevância a necessidade de conscientização dos manipuladores de alimentos no ambiente hospitalar, mostrando a importância nas práticas adequadas de higienização, pois a contaminação é resultado evidente da carente frequência e competência no processo de higienização das mãos.

Cabe aos profissionais de saúde em unidades hospitalares garantir capacitações e supervisão da equipe, além de condições físico-operacionais para a realização correta do processo de higienização das mãos. 


\section{REFERÊNCIAS}

AYÇIÇEK, Hasan et al. Assessment of the bacterial contamination on hands of hospital food handlers. Food Control, [turquia], v. 15, p. 253-259, 2004.

BRASIL. Ministério da Saúde. Programa de Prevenção e controle de Infecção Hospitalar (Infecção Relacionada a Assistência à Saúde - IRAS). Brasília 2004.

BRASIL. Ministério da Saúde. Resolução no 2004, de 15 de setembro de 2004. Dispõe sobre o Regulamento Técnico de Boas Práticas para Serviços de Alimentação. Resolução No 216, 15 de Setembro de 2004. Brasília, 2004.

BRASIL. Ministério da Saúde. Segurança do Paciente: Higienização das mãos. Brasília, 2009.

BRASIL. Ministério da Saúde. Dispõe sobre a obrigatoriedade de disponibilização de preparação alcoólica para a fricção antisséptica das mãos, pelos serviços de saúde do país e das outras providências. Resolução No 42, de 25 de Outubro de 2010. Brasília, 2010.

BRASIL. Ministério da Saúde. Segurança do Paciente e Qualidade em Serviços de Saúde: Critérios Diagnosticos de Infecção Relacionada a Assistência à Saúde. Brasília, 2017.

CDC. "Orientação para o controle de Enterobacteriaceae resistente a carbapenêmicos". Centro Nacionals de Doenças Infecciosas Emergetes e Zoonóticas, Centros de Controle e Prevenção de Doenças, p. 29, 2012.

CONTE, Vania Dariva et al. Qualidade Microbiológica de Águas Tratadas e não Tratadas na Região Nordeste do Rio Grande do Sul. Infarma, [rio Grande do Sul], v. 16, n. 11-12, p. 83-84, 2004.

CORREA, Maria Eduarda Gouveia et al. Mecanismo de Agressão e Defesa e sua Correlação com a Comissão de Controle de Infecção Hospitalar. Fagoc, Ubá, v. 2, p. 57-62, 2017.

CUNHA, Anderson de Souza; CUNHA, Marilene Rodrigues da. Toxinfecção alimentar por Staphylococcus aureus através do leite e seus derivados, bem como o elevado potencial patogênico de resistência às drogas. Saúde \& Ambiente, v. 2, n. 1, 2007. 
CUSTÓDIO, Janaína et al. Avaliação microbiológica das mãos de profissionais da saúde de um hospital particular de Itumbiara, Goiás. Ciências Médicas, Itumbiara, v. 18, n. 1, p. 07-11, 2009.

DUTRA, Cecília Breves; CAMPOS, Lízia Lenza. Pesquisa de Staphylococcus aureus, Salmonella e Escherichia coli em superfícies de latas de cerveja e refrigerante. Saúde da Faciplac, Gama, v. 4, n. 1, p. 19-27, 2017.

ELANDER, Richard. Industrial production of b-lactam antibiotics. Applied Microbiology And Biotechnology, v. 61, p. 385-392, 2003.

FELDHAUS, Jéssica Cristina et al. Colonização por MRSA no projeto piloto do estudo SHIP-Brasil. Revista Brasileira de Análises Clínicas, Pomerode, 2016.

FERREIRA, Jeane et al. Food handler-associated methicillin-resistant Staphylococcus aureus in public hospitals in Salvador, Brazil. Food Control, Salvador, v. 37, p. 395-400, 2014.

CARVALHO FILHO, Edvaldo Vasconcelos de et al. Monitoramento fisíco-químico e microbiológica de dietas enterais em unidade hospitalar pública da região nordeste do brasil. Alimentos e Nutrição Araraquara, v. 19, n. 2, p. 145-151, 2008.

GAUER, Daiana; SILVA, Gabriela Kniphoff da. Análise qualitativa e quantitativa da microbiota das mãos dos funcionários de um posto de saúde. Revista Brasileira de Análises Clínicas, Rio Grande do Sul, v. 49, n. 2, p. 206-212, 2017.

GAUTHIER, Lauraine et al. Diversity of carbapenemase -producing Escherichia coli isolates, 3 France 2012 -201 3. Antimicrobial Agents And Chemotherapy, [frança], v. 62, n. 8, 2018.

GUPTA, Neil et al. Carbapenem-Resistant Enterobacteriaceae: Epidemiology and Prevention. Clinical Infectious Diseases, v. 53, n. 1, p. 60-67, 2011.

HAMADA, Priscila Carneiro et al. Notes on risks analysis and security management in a hospital organization: a case study in a city of rio de janeiro. : a case study in a city of Rio de Janeiro. Produção e Desenvolvimento, Rio de Janeiro, v. 2, n. 1, p. 103-113, 2016.

KOCHANSKI, Samile et al. Avaliação das condições microbiológicas de uma unidade de alimentação e nutrição. Alimentos e Nutrição Araraquara, Alto Uruguai, v. 20, n. 4, p. 663-668, 2009. 
LABORCLIN. MRSA AGAR. Responsável técnico Elisa Hizuru Uemura. Pinhais: 2017. Bula.

LABORCLIN. KPC AGAR. Responsável técnico Elisa Hizuru Uemura. Pinhais: 2017. Bula.

LEÃO, Renata Campos et al. Ocorrência de enteroparasitos e coliformes termotolerantes nas mãos de manipuladores de alimentos de um hospital de ensino. Cadernos Saúde Coletiva, Uberaba, v. 26, n. 2, 2018.

MARMENTINI, Regiane Pandolfo; RONQUI, Ludimilla; ALVARENGA, Verônica Ortriz. A importância das boas práticas de manipulação para os estabelecimentos que manipulam alimentos. Facimed, Cacoal, 2010.

MARTINS, Suzana Cláudia Silveira et al. Perfil de resistência de cepas de Staphylococcus coagulase positiva isoladas de manipuladores de alimentos. Resultados da Pesquisa Resultados da Web Boletim do Centro de Pesquisa e Processamento de Alimentos, Fortaleza, v. 27, n. 1, p. 43-52, 2009.

MEDEIROS, Maria das Graças Gomes de Azevedo; CARVALHO, Lúcia Rosa de; FRANCO, Robson Maia. Percepção sobre a higiene dos manipuladores de alimentos e perfil microbiológico em restaurante universitário. Ciência \& Saúde Coletiva, Rio de Janeiro, v. 22, n. 2, p. 383-392, 2017.

MELETIS, Georgios; BAGKERI, Maria. Beta-lactamase and Carbapenemase Detection Methods: an overview of recent patents: An Overview of Recent Patents. Recent Patents On Anti-infective Drug Discovery, v. 9, n. 1, p. 1-5, 2014.

MENEZES, Joana Marilia Rodrigues; PORTO, Maria Luísa Souto; PIMENTA, Carla Lauise R. M.. Perfil da infecção bacteriana em ambiente hospitalar. Revista de Ciências Médicas e Biológicas, Patos, v. 15, n. 2, p. 204-207, 2016.

NORDMANN, Patrice; DORTET, Laurent; POIREL, Laurent. Carbapenem resistance in Enterobacteriaceae: here is the storm. : here is the storm. Trends In Molecular Medicine, v. 18, n. 5, p. 263-272, 2012.

NORDMANN, Patrice; NAAS, Thierry; POIREL, Laurent. Global Spread of Carbapenemas e producing Enterobacteriaceae. Emerging Infectious Diseases, v. 17, n. 10, p. 1791-1798, 2011. 
Organização Panamericana de Saúde. Organização Mundial da Saúde. Codex Alimentarius: Higiene dos alimentos: textos básicos. Brasília: 2006.

PONATH, Fabiane Seidler et al. Avaliação da higienização das mãos de manipuladores de alimentos do Município de Ji-Paraná, Estado de Rondônia, Brasil. Revista Pan-amazônica de Saúde, Ji-paraná, v. 7, n. 1, p. 63-69, 2016.

PROCOP, Gary W. et al. Koneman: diagnóstico microbiológico - texto e atlas colorido. 7. ed. Rio de Janeiro: Guanabara Koogan, 2019.

ROCHA, Lílian Alves. Microbiota das mãos de enfermeiras, estudantes universitários e técnicos de laboratório associada à lavagem higiênica. Universidade Federal de Uberlândia, Uberlândia, 2007.

RUBIN, Fabiane Horbach et al. Avaliação microbiológica das mãos, utensílios, e superfície dos manipuladores de alimentos em entidades do banco de alimentos de cruz altA. Unicruz, Cruz Alta, 2012.

SALLES, Raquel Kuerten de; GOULART, Rogério. Diagnóstico das condições higiênico-sanitárias e microbiológicas de lactários hospitalares. Rev. Saúde Pública, São Paulo, v. 31, n. 2, p. 131-139, 1997.

SANTOS, Mônica de Oliveira Bastos dos; RANGEL, Vanessa Pereira; AZEREDO, Denise Perdomo. Adequação de restaurantes comerciais às boas práticas. Higiene Alimentar, Rio de Janeiro, v. 24, n. 190, p. 44-49, 2010.

SEIBERT, Gabriela et al. Infecções hospitalares por enterobactérias produtoras de Klebsiella pneumoniae carbapenemase em um hospital escola. Einstein, Santa Maria, v. 12, n. 3, p. 282-286, 2014.

SILVA JÚNIOR, Eneo Alves da. Manual de Controle Higiênico Sanitário em Serviços de Alimentação. 7. ed. São Paulo: Varela, 2014.

SILVA, Lívia Viganor da et al. Evaluation of the synergistic potential of vancomycin combined with other antimicrobial agents against methicillin-resistant Staphylococcus aureus and coagulase-negative Staphylococcus spp strains. Memórias do Instituto Oswaldo Cruz, Vitória, v. 106, n. 1, p. 44-50, 2011.

TONDO, Eduardo César; BARTZ, Sabrina. Microbiologia e sistemas de gestão da segurança de alimentos. 2. ed. Porto Alegre: Sulina, 2019. 
WIETHAN, Jéssica Gracioli; BECKER, Ana Paula. Avaliação da presença de micro-organismos multirresistentes na microbiota de estudantes durante a graduação. Disciplinarium Scientia, Santa Maria, v. 19, n. 3, p. 311-319, 2018.

ZANCANARO, Fernanda et al. Condições higienicossanitárias das instalações e dos procedimentos de elaboração e distribuição de fórmulas infantis em lactário de hospital de Itajaí, SC. Higiene Alimentar, Itajaí, v. 31, n. 272, p. 56-61, 2017. 
